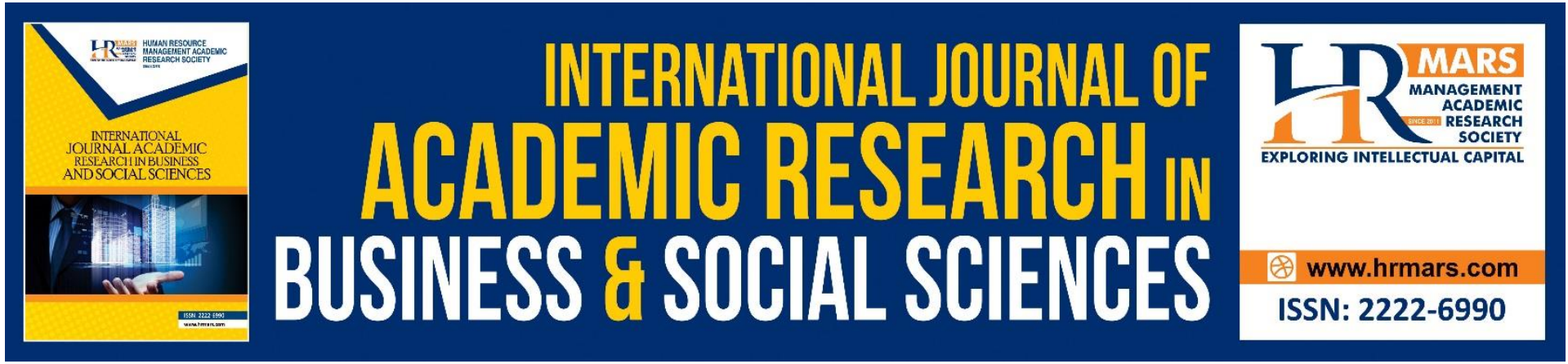

\title{
Leadership as a Vehicle for Organisational Commitment across the Malaysian Health Sector: A Medical Practitioner's Perspective
}

Pubadi A/L Govindasamy, Nor Wahiza Abdul Wahat, Khairuddin Idris, Siti Noormi Alias

To Link this Article: http://dx.doi.org/10.6007/IJARBSS/v11-i8/10794 DOI:10.6007/IJARBSS/v11-i8/10794

Received: 03 June 2021, Revised: 05 July 2021, Accepted: 27 July 2021

Published Online: 22 August 2021

In-Text Citation: (Govindasamy et al., 2021)

To Cite this Article: Govindasamy, P. A., Wahat, N. W. A., Idris, K., \& Alias, S. N. (2021). Leadership as a Vehicle for Organisational Commitment across the Malaysian Health Sector: A Medical Practitioner's Perspective. International Journal of Academic Research in Business and Social Sciences, 11(8), 1029-1046.

Copyright: (c) 2021 The Author(s)

Published by Human Resource Management Academic Research Society (www.hrmars.com) This article is published under the Creative Commons Attribution (CC BY 4.0) license. Anyone may reproduce, distribute, translate and create derivative works of this article (for both commercial and non-commercial purposes), subject to full attribution to the original publication and authors. The full terms of this license may be seen at: http://creativecommons.org/licences/by/4.0/legalcode

Vol. 11, No. 8, 2021, Pg. 1029 - 1046

Full Terms \& Conditions of access and use can be found at http://hrmars.com/index.php/pages/detail/publication-ethics 


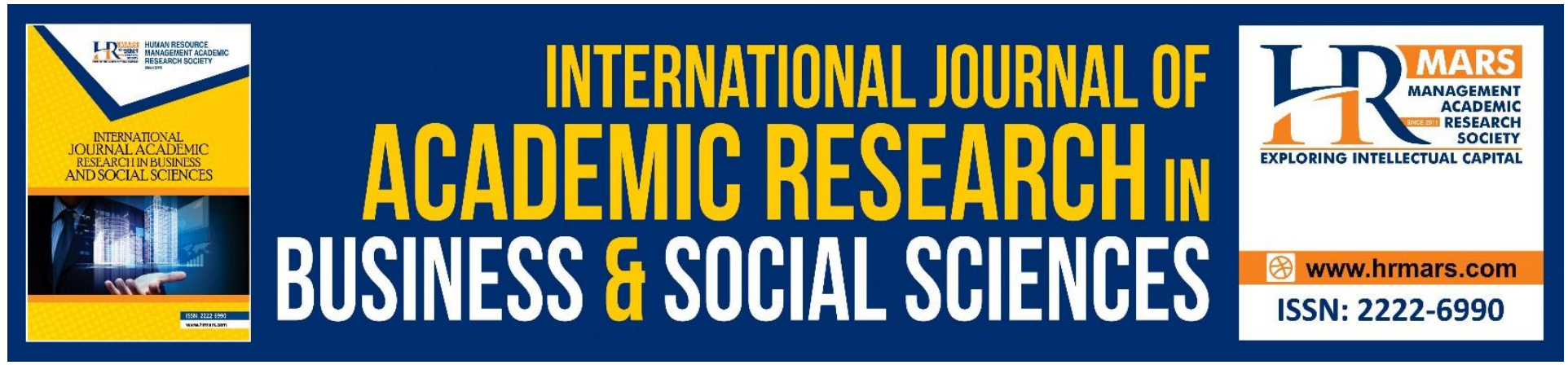

\title{
Leadership as a Vehicle for Organisational Commitment across the Malaysian Health Sector: A Medical Practitioner's Perspective
}

\author{
Pubadi A/L Govindasamy, Nor Wahiza Abdul Wahat, \\ Khairuddin Idris, Siti Noormi Alias \\ Faculty of Educational Studies, Universiti Putra Malaysia, Serdang, Selangor, Malaysia \\ Email:wahiza@upm.edu.my
}

\begin{abstract}
In the field of management, leadership styles and organisational commitment are significant subjects to investigate. The purpose of this research is to look at the leadership styles and organisational commitments of medical practitioners in Melaka's State Health Department (Jabatan Kesihatan Negeri Melaka (JKNM)). The study looked at the most prevalent leadership styles as well as the different types of organisational commitment among JKNM's medical practitioners. The study employed a qualitative approach to collect data through 10 in-depth interviews with purposively selected medical practitioners. The Nvivo 12 software was used to analyze the interview transcriptions and define the emerging themes and codes. The results indicate that four major themes, namely, vision, commitment, attitude, and leadership style were crucial toward these findings. The findings added to the expanding body of knowledge in terms of establishing the leadership context (autonomy, commissioning, and personalization), as well as providing possibilities to embed leadership styles and organisational commitments in the healthcare sector. This enhanced the significance of the findings and is crucial in closing the gap in the sluggish growth of research on leadership styles and organisational commitments in the healthcare industry.
\end{abstract}

Keywords: Leadership Styles, Organizational Commitment, Healthcare Sector, Medical Practitioners, Jabatan Kesihatan Negeri Melaka (JKNM)

\section{Introduction}

The last 50 years have seen substantial strategic leadership work. It is not surprising that scholars have concentrated on this primarily, as leadership iscrucial toward organizational success (Cardinal et al., 2017). Without strategic and efficient leadership, representatives of the organizations have trouble maintaining it's competitiveness, and efficiency. Leadership styles have been a popular area of research in the management profession in recent years. Many academics believe that leadership styles are an important factor in influencing how members of an organization operate (Aydın, 2018). 
Organizational leaders in various areas of the globe have been accused of using top-down, command-and-control leadership styles to lead their subordinates, which frequently generates unfavorable responses from their subordinates (workers), and impedes cordial interactions between the two sides (Akinbode \& Fagbohunde, 2012). The consequences of these leadership styles include, among others, the decrease in the motivation levels of the staff, and the loss of employee involvement. It is typically evident, because these employees have no imminent ability to leave the organization for some reason, and become emotionally disconnected from the organization (Nasurdin et al., 2014).

The link between different leadership styles and team performance was examined using a leadership process which impacts the team growth across a private research institution, and including the mediating impact of information exchange and team coordination (Elrehail, et al., 2018). Voon et al. (2011) discovered how leadership models influence the happiness of employees in Malaysia's public sector organizations. They used considerations such as incomes, autonomy, job stability, and versatility in the workplace. From these variables, they found a strong relationship between disruptive leadership and work satisfaction levels. Similarly, Fang et al. (2009) found that leadership styles may influence organizational commitment and job satisfaction, and that employee contentment levels can influence an organization's and employee's performance.

Linehan (2017) argued that leadership is primarily patriarchal, and follows conventional beliefs, expectations and values, and concerns. Goh and Soutar (2005) claimed that leadership is heavily influenced by immediate and large families, clans, and tribes. Their research explored the link between corporate leadership and business ethics, and led to enhancing the quality of corporate life, which could have a significant effect on both the organization's members, and the wider society.

A study by Lo et al (2010) clarified the expectations of the employees about the management styles of transactional or disruptive leadership, and the interaction between them, as well as, their expectations about being rewarded by their management, in their innovation environment. Gottfredson and Aguinis (2017) stated that management habits can specifically improve the interaction between management style and organizational performance, and can impact an employee's loyalty and happiness in an organization. Podsakoff et al (1990) implied that leadership actions would directly influence the trust and happiness of employees in an organization, and the nature of corporate citizenship. Leadership is a fairly constant behavior pattern which fundamentally characterizes a leader's traits.

Based on the description above, it is evident and essential for the values of leadership (especially the style embraced by the leader), and employee's dedication toward the organisation, for achieving either job, or organizational goals and objectives. Leadership has also been seen as a vital aspect and management feature that helps control an employee's commitment within the organization, and the accomplishment of corporate goals (Abasilim et al., 2018).

It has also been noted that there has been a significant academic focus given to the connection between leadership styles, and employee engagement. Many leadership studies have recognized a variety of leadership styles that leaders follow for leading an organization 
(Kelly \& MacDonald, 2019; Yukl, 2012). To name a few, transformation leadership, transactional leadership, and laissez-faire leadership styles, which have been listed as the most widely used models in studies on organizational leadership (Abasilim et al., 2018; Rehman et al., 2012). Similarly, employees in a firm typically show three main forms of participation, i.e., effective, normative, and continuous commitment (Othman et al., 2013).

Previous studies (Emery \& Barker, 2007; Yiing \& Ahmad, 2009; Chen et al., 2015) have repeatedly stressed on the highly positive influence of leadership styles and organizational commitment among medical practitioners. To date, however, no research has specifically delved into the notion of assessing various factors which influence the leadership styles and organizational engagement among Malaysian medical practitioners.

The present study endeavors to study the leadership styles and organizational commitment among medical practitioners at the Melaka State Health Department [Jabatan Kesihatan Negeri Melaka (JKNM)]. Specifically, this research would offer important insights into the factors which influence these leadership styles, and the organizational commitment among medical practitioners at JKNM.

Two main research questions (RQ) were put forth to guide the current study:

RQ1: How do leaders get medical practitioners to commit toward the organization?

RQ2: Why do leaders choose a particular leadership style?

\section{Methodology}

\section{Research and Sampling Design}

Following these research objectives, the current study utilized semi-structured interviews to assist in the interpretation of the data, and to facilitate the interpretation of the in-depth viewpoints of the participants (Creswell \& Clark, 2017). The selection of the study location, types of respondents, sample size, and sampling procedures have been carefully designed to ensure that the data obtained are accurate and valid. The population for this research consisted of medical practitioners working in the Melaka State Health Department [Jabatan Kesihatan Negeri Melaka (JKNM)], Malaysia. It is important to understand that not all employees inside the organization have an equal strategic interest (Lepak et al., 2006). The workflow of medical practitioners are highly complex, and distinct from that of other healthcare professionals.

As a result, the researcher purposefully chose a sample group of participants who might best shed light on the specified study problem's conclusions. Qualitative approaches, according to Silverman (2013), are soft, flexible, subjective, political, and grounded. The qualitative approach was expected to benefit the current study in its attempt to explore and deduce the phenomenon of interest, particularly in highlighting the possible challenges and conflicts in the healthcare sector from the individual perspectives of multiple stakeholders, to help shed light on the factorsof flexibility and subjectivity.

This research employed a non-probability purposive sampling technique. Purposive sampling is appropriate when a study defines a certain sample selection criterion (Cooper \& Schindler, 2014). This research focused on medical practitioners (e.g. medical doctors, dentists, and pharmacists), who are currently working in JKNM, Malaysia. The most recent total population 
was another reason for the use of the non-probability purposeful sampling technique, as the last overall population census of medical practitioners in Malaysia was released on $31^{\text {st }}$ December, 2013.

The subjecta for the present study were composed of 1,407 Melaka public medical practitioners, of which, 1,050 were medical doctors, 136 dentists, and 221 pharmacists. Fixing an appointment to interview these medical practitioners was not an easy task. They are always busy with their patient care and administrative tasks. For the face-to-face interview, 10 medical practitioners, consisting of 4 doctors, 3 pharmacists, and 3 dentists, expressed their willingness to contribute toward the interview.

\section{Interview Design}

Interviews in this study refered to the seven-stage interview process professed by Kvale and Brinkmann (2009). They covered the seven steps of conducting in-depth interviews, i.e., thematizing, planning, interviewing, transcribing, analyzing, confirming, and reporting. This study considered the approach of a semi-structured interview, because this approach provided flexibility to present any supplementary questions to the participants during the interview session, based on the topic being discussed. Moreover, this approach did not limit the participant's responses in any way.

For this study, the order and wording may not be exactly similar to that of the established procedure, despite a nearly similar number of questions which were posed to the participants during the interview. There may be much more probing questions for the participants, to acquire an in-depth insight on the issues being discussed. A face-to-face interview provided an opportunity for information-rich communication between the interviewer and interviewees, because the non-verbal language of the participants could be observed as well.

Validity and Reliability Guba and Lincoln (1994) proposed trust and credibility as requirements for determining the standard of a study. To ensure trust and accuracy, the current research was compiled within a specified criteria, and followed a rational research design. Data adequacy was largely dependent on the number of respondents, but the number alone had nothing to do with the consistency of the data adequacy (Morrow, 2005).

Patton (2014) indicated that the validity, importance, and insights produced through qualitative inquiries are much more related to the richness of the knowledge of the selected cases and the analytical capabilities of the researcher, than the sample size. Sufficient evidence is not obtained by simple numbers, but the sufficient number of research participants. Usually, data are collected to the point of depletion, once the new data are not available (Guba \& Lincoln, 1994). As such, sampling methods, consistency, duration, and the depth of interview data, as well as a range of evidence, are more important than the sample size.

The reliability test was performed to ensure that all researchers would draw the same conclusions using the same research methodology as that of the original researcher. The purpose of the reliability test was to reduce biases and mistakes. Through reporting accurately and making the activities as effective as possible in the procedures of the case 
study, other researchers would be able to replicate the process, and achieve the same results. Therefore, the case study protocol will help to improve the reliability (Yin, 2017).

\section{Data Collection Method}

Data collection isconsidered to be an important aspect of research analysis, as it allows the researcher to collect information used to evaluate the research goals (Fink, 2000). The main method of collecting data for this study was through the interviewa. Throughout the interview, the researchers explained the protocol to each participant, and how their participation in the study was important, and reminded them that their responses were handled with absolute confidentially at all times.

In order to depict honest thoughts and feelings, the interviewees should feel comfortable (Cohen, Manion \& Morrison, 2000). It took about 20 to 45 minutes for each interview to be completed. The interviews were recorded with the permission of the participants (Stockdale \& LeMay, 2001). All interviews were carried out in English, and in some instances, mixed with Bahasa Malaysia, of which, the interviews were transcribed later.

\section{Data Analysis Method}

Qualitative research data collection is very distinct from quantitative research (Patton, 2014). The analytical techniques used in this analysis included data transcription and coding, as well as analytical methods. The major goal of the interviews were to give detailed, rich accounts of the participant's experiences, viewpoints, and comments, from across the various health institutions. The interview texts were read, analyzed, and interpreted thoroughly, and the study questions help define the themes for each node. This method ensured that the transcripts were put at the right nodes in the statements or sentences.

The major themes were also derived using the interview questions as a starting point. To compress a large quantity of data to a reasonable level, the open coding approach categorized the data into much more precise themes, before arranging them under the developing themes throughout the data axial coding process. The researchers were also able to visualize the data across several themes, to point out the similarities and contrasts within and between the case studies, by using cross-case tabulations (Eisenhardt, 1989). New themes were identified during the inductive coding process, if the findings did not fit with the study's questions.

\section{Ethical Consideration}

Researchers should concentrate on all aspects of research ethics, which are deemed appropriate from the perspective of the study, to render the studies true, accurate, and acceptable (Sekaran \& Bougie, 2016). For data collection, the researchers followed the ethical review process administered by the university. The ethical approval of this research was provided by the University Committee. Some aspects of research ethics which the researcher must consider when carrying out this analysis are data management, privacy, and informed consent letters.

Data management in research is part of research activities that lead to the efficacy of the study. It is found that data processing is subjected to some unique problems, which may deviate from research ethics. The researchers must ensure that the data is ethically, and 
legally obtained. Also, all sorts of sensitive information about the informants must be carefully handled, along with the guarantee that they cannot be accessed by any third party without a link to the study (Walliman \& Walliman, 2010).

Furthermore, the researchers must ensure that informant's privacy remains a part of ethical standards, both before and after the report. Confidential information, or any other information relevant to the study, must be protected. Research must always preserve confidentiality in order to not compromise the privacy of the organization and the informants. The researcher is also responsible for maintaining the protection of the data gathered from across different individuals (Babbie, 2010).

The current research work ensured that informed consent letters were sent to the participants as part of the qualitative process. The letter contained a short introduction to the research, its aims, and research goals. The participants were also asked to suggest other potential participants for this study. Individual informed consent letters were then prepared for the individuals who agreed to participate in the research.

\section{Research Findings}

\section{Description of Participants}

The participants in the current study consisted of 10 medical practitioners who worked at JKNM. They were the most eligible participants for this research. They fulfilled the selection criteria of this study, and qualified in terms of their knowledge, skills, and experiences in JKNM. All participants were identified anonymously by codes, to protect their confidentiality. Table 1 describes the participant's code, gender, age, and working experience.

Table 1. Participants Description

\begin{tabular}{lllll}
\hline $\begin{array}{l}\text { Participant } \\
\text { Code }\end{array}$ & Gender & $\begin{array}{l}\text { Age } \\
\text { (years) }\end{array}$ & $\begin{array}{l}\text { Working } \\
\text { (years) }\end{array}$ & Experience \\
\hline MP01 & Female & 31 & 5 \\
MP02 & Female & 30 & 4 & \\
MP03 & Female & 32 & 5 & \\
MP04 & Female & 38 & 12 \\
MP05 & Female & 40 & 12 \\
MP06 & Female & 39 & 8 \\
MP07 & Male & 27 & 2 \\
MP08 & Female & 27 & 2 \\
MP09 & Female & 39 & 15 \\
MP10 & Female & 37 & 7 & \\
\hline
\end{tabular}

Themes of the Study

Each participant was given an information sheet, a consent form, and a set of questions via email before the interview, to allow time for the collection of their thoughts. The consent form was either signed at the start of the face-to-face interview, or was read aloud during the conversation, to gain a verbal consent before the interview commenced. Furthermore, each interview was held with a proper introduction, followed by the topic under study, which was audio-recorded with their permission. 
The interviews were analyzed and interpreted using Nvivo 12. During the coding process, the topics were extracted inductively from the results of the interviews. The in-depth interview data were then analyzed using a thematic framework analysis, to identify the emerging patterns and themes. The themes were added systematically to the codes, and rearranged as per the thematic structure. Once the major topics were illustrated, a structure of categories for each transcript was developed. Four themes were identified, i.e., vision, commitment, attitude, and leadership style. Figure 1 illustrates the four identified themes in the study.

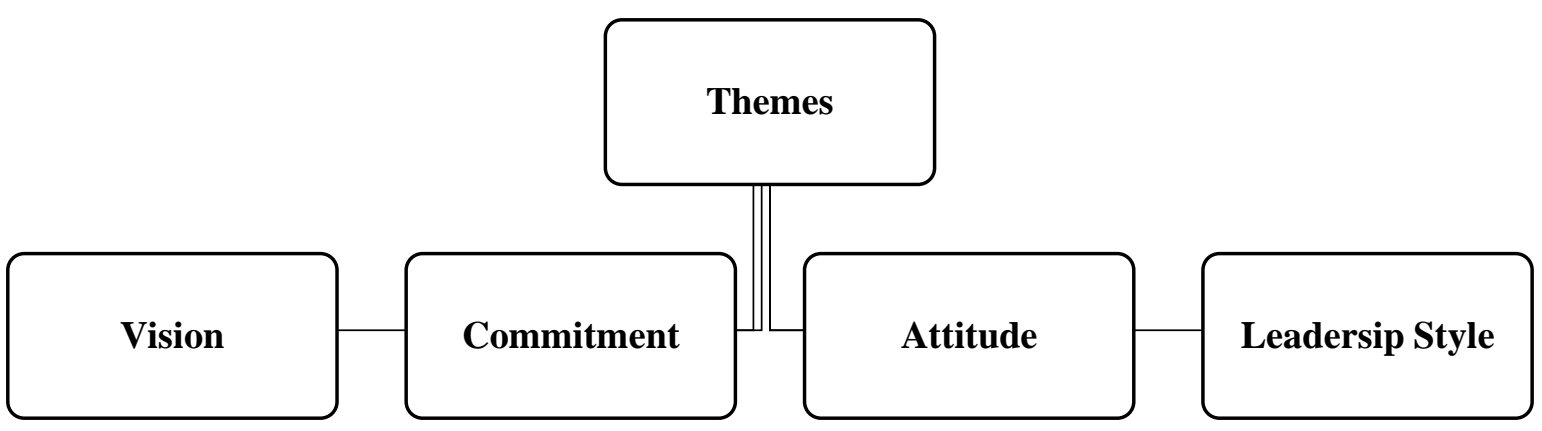

Figure 1. Themes of the Study

The current study used Morrow and Smith's (2000) proposed qualitative procedures to evaluate the conversation transcripts, including the code, interpretation, and current data, according to the themes. To reinforce the interpretations of the debate, the statistics were provided with direct quotations, to illustrate the patterns and diversity of their viewpoints. The interview guide was developed to facilitate the researcher in terms of generating the necessary information to explore the following research questions:

\section{Research Question One: How Do Leaders Get Medical Practitioners to Commit to the Organization?}

Because of the first research objective in the study, the participants were asked to share their understanding of their organizational commitment, and how they saw it, as well as what problems they faced as medical practitioners. Based on the question, participant MP02 stated that the following:

"Having a vision among medical practitioners for an optimal working environment which is committed to the organization, is a critical part for leaders, in being able to get medical practitioners to commit to an organization" [MP02].

Supporting participant MP02's statement, participants MP05 and MP07 stated that: "Followers are much more inspired to act when leaders articulate a strong vision that others agree with, and want to be a part of." [MP05]

"Leaders must present a broad picture of what we're all attempting to accomplish, the goals we're all aiming for. But it's just as essential for leaders to talk about how each medical practitioner in the company may acquire a 
sense of how his or her job ties to the business's goal or vision commitment, which takes more time and effort." [MP07]

In continuation of the above statement, participant MP04 also highlighted that:

"Vision commitment provides a team direction, and helps individuals focus on knowing what it takes to do a task successfully. It also inspires and allows everyone involved to stay abreast in terms of knowledge on how management expects to achieve specific objectives and commitments." [MP04]

Similarly, participants MP08 and MP10 also expressed that:

Vision motivates people to take action and make commitments. A compelling vision attracts people, ideas, and other resources. It generates energy and causes changes to occur. Furthermore, it motivates people and organizations to commit, persevere, and offer their all." [MP08]

"Vision is a useful tool for establishing plans, defining goals and objectives, making choices, coordinating and assessing work, and helps keep medical practitioners and groups focused and united, especially in difficult situations." [MP10]

In addition to vision and commitment, the attitude of the practitioners and the styles of leadership is key toward evaluating the commitment of the medical practitioners. In the case of doctors, the stressful nature of their profession is part of their mindset. Health professionals are highly trained practitioners, and their positions require them to not only be specialized in technological knowledge, but the art of connecting with people, as well as their constant desire to help. There has been a sharp shift in the dynamics of interactions between medics and the public. The relationship between the two has taken on a much more formal overtone, with medical practitioners being grouped into a structured management-organized sector.

Management needs to be aware of a loss in productivity, which is typically led by a decrease in job satisfactions levels. From this perspective, the attitude of physicians towards their work and workplace must be understood.

Participant MP07 mentioned that:

"The attitude shown by the leaders is also a factor which makes medical practitioners commit their organization. However, these attitudes vary across different leaders and leadership styles" [MP07].

Furthermore, participant MP01 expressed:

"By watching our bosses's attitude... for now, my bosses are all good, as they are very patient and also cooperative with us... so from that, I learnt that leadership... it's meant to be leading by example. [MP01]

However, according to participant MP03:

"In Malaysia, what I notice is if you keep your staff happy... in a sense of focus, you inquire their well-being, and they are much more supportive of their work. 
They should not be task-oriented, they should care, they should have more support to get the job done better. This means that... they set the target, and also consider the well-being of team". [MP03]

Participant MP03 mentioned that medical practitioners should not be task-oriented, they need to be caring, and they should have more support to perform their jobs much better.

Participants MP06 and MP09 illustrated the following:

"The attitude of medical practitioners toward the profession in general, and the patient in particular, will influence various elements of his or her functioning to a great extent. Collaboration with other experts, healthcare priorities, and medical decision-making, are all influenced by one's attitude. The most significant area impacted by attitude might easily be regarded as the quality of communication with the patient." [MP06]

"We must realize that the quality of the relationship between medical practitioners and leaders is part of the leadership competence of the medical practitioners, and can play an important role in the outcome of a relationship. After leader interventions, medical practitioners who are anxious, doubtful, or hesitant, have longer convalescence times and more problems, than those who are confident and comfortable." [MP09]

In summary, the responses provided by the participants seem to reflect the importance of having a vision in the organization, which will lead medical practitioners toward commiting to the organization. This highlights that JKNM and the medical practitioners have a clear sense of purpose, and positive commitment toward the organization. It means that organizations such as JKNM need to have a much larger picture of the medical practitioner's commitments, than simply setting and reaching short term goals, and tackling problems as they come along.

Given the increasingly dynamic leadership styles and organizational commitments, it is critical for JKNM to proactively improve their capabilities through first, unifying and gathering points, or common interests among medical practitioners, and feeling as though they are a part of a greater infrastrucutre. Not only does this provide deeper meaning for the medical practitioners, but it also helps unify medical practitioners into a team that is organized, focused, and working together to contribute toward the vision.

Furthermore, inspiring the medical practitioners to have a powerful vision will have a clear motivational effect on everyone within the organization. This eventually will create energy and enthusiasm, increasing commitment, and fostering change among medical practitioners. This is especially important in difficult or stressful times, as having a clear vision will produce persistence and remind the medical practitioners why they must commit to the organization.

Finally, it provides a focal point for goal-setting and organization planning, with a sense of purpose and direction for the medical practitioners, and this will help the medical practitioners to define short and long-term goals, and guide the decisions they make along the way towards organizational commitment. 


\section{Research Question Two: Why Do Leaders Choose A Particular Leadership Style?}

Because of the second research question in the study, the participants were asked to share their understanding of leadership styles (transformational, transactional \& laissez-faire), and how the medical practitioner find their leader's actions to be inspiring, leading them to be committed toward their profession. When faced with the challenges of modern healthcare, organizations and medical practitioner have a higher capability for demonstrating leadership. Regardless of professional ethics or their field of specialization, medical practitioners playa leading role in the healthcare team, and are considered to be ultimately responsible for the overall outcome of the organization.

Based on the question, participant MP02 mentioned that:

"Because leadership and management abilities are necessary to assure the provision of high-quality patient care, leadership has become a crucial ability for medical practitioners. A medical practitioner's active engagement in leadership and management appears to be helpful, and there have been favorable connections discovered between medical practitioners and organizations, in terms of clinical results and overall performance." [MP02].

Despite this, participant MP09 expressed the following:

"Interprofessional collaboration is essential for clinical quality, therefore, leadership and management abilities are required at all levels. Healthcare systems across the world are fast-evolving organizations confronted with a variety of difficulties, including budgetary limits, increased demand for responsibility, more regulation, and changes in patient demographics. This is especially true with the aging population in Malaysia" [MP09]

Almost similarly, MP01 stated:

"Hospitals develop leaders at all levels, who can manage the organizational and system changes necessary to improve health through innovation in the health profession's education and patient care, and its research. These leaders need to help define the future, align people with a vision, and remove obstacles to allow people to see this vision" [MP01]

Even though organizational and system changes are necessary to improve healthcare through innovation, participant MP03 expressed:

"Medical practitioners are expected to provide leadership skills that enhance team functioning, the learning environment, and/or the healthcare delivery system." Many hospitals lack formal leadership programs, which may reflect the time constraints of the existing curricula, its limited resources, and beliefs that leadership cannot be taught, as well as a lack of consensus on leadership contents, among other factors" [MP03]

In supporting participant MP03's viewpoint, participant MP06 emphasized:

"The key qualities of participants for determining leadership include, the quality of emotional intelligence, which includes self-awareness, empathy, cultural sensitivity, professionalism, motivation, inspiring commitment, confidence, and creativity" [MP06] 
MP02 described it as:

"Communication, conflict resolution, time management, negotiation, delegation, teamwork, and community service are key skills which have been identified by the study participants, and are necessary outcomes" [MP02]

Experiential and leader-led learning as key strategies for cultivating future leaders, are highly favored. Explicit leadership curriculum include role play, staff training, group experience, leadership experiences for medical professionals, involvement in high-performing initiatives, and mentoring leadership learning plans, which can be used to enhance medical practitioners.

Participant MP08 illustrated leadership styles, which plays an integral role in enhancing quality measures among medical practitioners:

"Leadership topics suggested by medical practitioners included the structure of the JKNM, team work skills, decision-making, and negotiating skills among leaders. Patient safety was seen as particularly important, and the involvement of medical practitioners in leadership and management has a beneficial effect on healthcare services, along with the quality of patient care. If more of tomorrow's medical practitioners are going to engage in leadership and management, it is necessary to educate them now" [MP08].

Apart from the medical practitioner's attitude towards leaders and the workplace, being a medical practitioner means more than simply being a good clinician. In their day-to-day role, the medical practitioners can provide leadership to their colleagues, and visions for the organizations in which they work for, as well as the profession as a whole. However, unless medical practitioners are willing to contribute toward improving the quality of services, and to speak up when things are right, medical practitioners are likely to suffer the consequences.

Perhaps, the realities of modern medicine offer the best medical leadership possibilities available. Naturally, this availability means that leaders must step in, and take advantage of the opportunities. The incredibly fast pace of change, and the increasing importance of cost pressure in increasingly complex organizations, are only a few challenges that modern physicians face.

According to participant MP05:

"Leadership roles in medical, as well as healthcare in general, have both multiplied and grown in complexity, and medical practitioners are being looked at to bridge the gap between practitioners/clinicians and managers. This suggests that both are a great challenge, as well as an unprecedented opportunity. As the next generation of health professionals, we can already see the complex world of medical and healthcare that awaits medical practitioners" [MP05].

In supporting participant MP05's statement, participant MP08 highlighted:

"Although it poses many challenges to us, if we prepare ourselves adequately, and get involved early-on, we have the potential to make great strides, both within and outside the worlds of medicine and healthcare" [MP08]. 
Participant MP08 mentioned that medical practitioners pose many challenges: "Good leadership isn't just for those in positions of responsibility. It involves whole teams working together to help deliver and improve patient care. In this guide, we explore your role in management and leadership" [MP03].

In summary, models of leadership play an integral role in strengthening the medical practice's efficiency indicators. The effect on health conditions is varied across the different types of leadership, whereas the current healthcare divide can be broadened, or narrowed. The present and potential aims of both communities are to resolve the healthcare leadership void, in a developing and demanding environment. For medical and medical organizations to improve their quality indicators in healthcare, they must ensure technical and professional expertise, build necessary capacity, and elevate the right corporate culture, all while balancing the priorities for leadership and existing skills.

\section{Discussion}

\section{Medical Practitioners' Commitment to the Organization}

Given the first research question of the study in understanding how leaders get medical practitioners to commit to the organization, the responses offered by the participants appear to indicate the value of creating an organizational vision which can contribute toward the dedication of medical professionals in the organization. This indicates that JKNM and the medical practitioner have a strong sense of mission and attitude towards the organization's contributions. This also suggests that organizations such as JKNM have a much broader view of the dedication of medical practitioners, than merely setting and meeting short-term targets, and addressing challenges as they come along. Because of the highly diverse leadership style and determination of the organization, it is essential for JKNM to proactively strengthen its capability by firstly, unifying the medical practitioners, and making them feel as if they were part of a larger goal. This not only provides medical practitioners with a greater purpose and drive, but it also serves to unify medical practitioners into a team that is structured, centered, and works together to contribute toward the vision.

Secondly, it encourages and provides a direct motivating impact on those within the organization, by encouraging medical professionals to have a strong vision. Ultimately, this will stimulate motivation and excitement, increase dedication, and encourage progress among medical practitioners. This is extremely important for challenging or frustrating times, when having a clear goal will help to generate commitment, and remind medical practitioners that they need to continue to contribute toward the organization. Finally, it provides medical practitioners with a sense of mission, and focuses as a focal point for goal-setting and operational preparation, which can enable medical practitioners to identify short and longterm priorities, and lead the choices they make towards organizational engagement.

It is, thus, possible to identify the numerous theories, cases, and models which influence the current leadership strategies applicable to the healthcare context . Efficient leadership guidance should focus on the dynamic links between values of leadership, culture, skills, and the organizational context. This dynamic, backed by a high level of team and organizational consciousness, must operate at the development level of a leader. Leadership growth has reached a crucial juncture, and the leader's position can be defined as that for ensuring that subsequent leaders are ready to progress in the ever-changing health care setting. 


\section{Leaders' Particular Leadership Styles}

The second research question highlighted the reason for leaders to choose a particular leadership style. The desire to lead is a crucial attribute that all medical practitioners, especially allied health providers, require in order to be competitive in the healthcare field. In the business environment, leadership, personality characteristics, and leadership styles, have been thoroughly studied (Rad \& Yarmohammadian, 2006). But, there has been even less observational leadership literature on medical practitioners (Braveman, 2006). Several studies investigated the leadership styles of medical practitioners (e.g. Brown et al., 2014), and the value of efficient and strategic leadership among medical practitioners was offered (Peachey, 2002). An occupation-based model of leadership was suggested.

The leadership characteristics of medical practitioners have also been explored to a small degree (Dudek-Shriber, 1997; Snodgrass, et al., 2008). Very little research, however, has been conducted to examine the leadership qualities of medical practitioners, and new practitioners. According to the findings, effective leaders will usually use all dominant styles, whereas, ineffective leaders typically adhere to one form of leadership, and do not demonstrate versatility or adaptability based on the demands of the situation (Lincoln, \& Keller, 2018). Governmental priorities, economic climate, evolving laws and practices, reduced payment, intensified competitiveness, and a more educated, assertive clientele, are strongly affected by healthcare organizations (Braveman, 2006).

Organizations in the healthcare field must, however, continuously respond to these pressures. Both higher executive tiers, and lower levels of the healthcare managerial hierarchy, are influenced by these external factors (Nugus et al., 2018). In the end, medical practitioners find themselves needing training in both formal and informal leadership positions (Braveman, 2006). Executives also have strong standards for medical practitioners, who supervise innovative problem solving, and work as successful participants in multidisciplinary teams.

In summary, medical practitioners can also be called upon to hold leadership roles outside of the working world, such as memberships in voluntary agencies on management boards, or memberships in trade associations. Collaboration, conflict management, a united and mutual vision/goal, encouragement, creativity, career support, improved individual awareness, confidence, and personal influence, are generated through successful leadership (Blank, 2019). It has been speculated that an individual's capacity to acquire or embrace these attributes, correlates with these forms of personality (Bono \& Judge, 2004).

The results can be outlined by indicating that medical practitioners have more transformative qualities using the principles of transformational leadership, as a means of predicting good leadership (transformational leaders are encouraging, optimistic role models, concerned about followers, encouraging, and forcing followers to be innovative, and take chances).

\section{Implications of the Study}

Researchers have extended the general significance of leadership styles and organizational commitment, to include ideas about inventiveness and imagination in recent years (ReiterPalmon et al., 2004). Policymakers need to take greater account of the challenges faced by the medical practitioners at the implementation level, for developing the leadership context 
(autonomy, commissioning, personalization). This helps to offer opportunities to embed leadership styles, and organizational commitments in the healthcare sector. When leadership styles and organizational commitments are made more accessible, innovation could be built much more easily. Medical practitioners need stronger connections between creativity, and the emerging managerial policies, so that the leadership styles and organizational commitments are integrated within these developments, and can be reciprocally enhanced through creativity.

A medical practitioner also needs to build a much more coherent "leadership offer," which, then actively integrates into the healthcare and self-reliance environment. Therefore, $a$ renewed program which highlights these issues is crucial, not only for the demanding leadership styles and organizational commitments, but for warning of the contextual problems it faces, and for providing space and encouragement for its development. This will also have a very strong effect for incorporating additional space, and enhanced incorporation into the program, and several common experiences to promote and improve individual strategies, leadership styles, and organizational commitment among medical practitioners.

\section{Conclusion}

The understanding gained by this study on the policy and implementation of leadership styles and organizational commitment among medical practitioners showed that numerous stakeholders in the Malaysian healthcare system have their own interpretations of leadership styles, and organizational commitments. The findings of this study will hopefully influence the development of leadership styles, and organizational commitments among the medical practitioners.

Medical practitioners demonstrate a wide array of innovative and creative work in healthcare, and are encouraged to actively and systemically demonstrate positive attitudes. The associated stakeholders in this context need to be very mindful of the need and value of leadership styles, and organizational commitments. The problems and barriers found, do not emerge from the lack of common desire, knowledge, or concept of leadership styles and organizational commitment, but, from the contextual challenges and pressures which threaten leadership in the healthcare sector. In some aspects, it arises much more from the processes and the attitudes in the system, than from any genuine, or perceived lack of a common definition.

\section{Limitations of the Study}

The first limitation highlights that, there were very few medical practitioners who were interviewed, and that the interviews were quite short, as the medical practitioners were busy. Perhaps, follow-ups would have allowed the researchers to check the interpretations, and understanding of their personal views on leadership styles and organizational commitments, and garner their opinion of the overall picture of the leadership agenda. This would have helped to triangulate information from other sources, which would have added to both the depth and quality of the area of research.

The second limitation concerned the results of this study. Medical practitioners were employed as respondents, and a semi-structured interview was carried out. The sample could therefore be biased, because the sample included the medical practitioner's professional 
experience, and knowledge. The understanding of these figures depends on the researcher's subjective evaluation. The third limitation was related to the problems in finding appropriate literature information relevant to the study area, as only a limited amount of work was available on leadership styles, and organizational commitment solutions.

\section{References}

Abasilim, U. D., Gberevbie, D. E., \& Osibanjo, A. (2018, October). Canonical analysis of perceived leadership styles and employees' commitment in Nigeria. In ECMLG 2018 14th European Conference on Management, Leadership and Governance (p. 317). Academic Conferences and publishing limited.

Akinbode, G. A., \& Fagbohunde, O. B. (2012). Leadership and Organisational Factors as Predictors of Employees Organisational Commitment in Nigeria: An Empirical Analysis. Business and Management Research, 1(2), 69-87.

Aydın, B. (2018). The role of organizational culture on leadership styles. MANAS Sosyal Araştırmalar Dergisi, 7(1), 267-280.

Babbie, E. (1990). Survey Research Methods ( $2^{\text {nd }}$ ed.). California: Wadsworth Inc.

Blank, S. (2019). Managing organizational conflict. McFarland.

Bono, J. E., \& Judge, T. A. (2004). Personality and transformational and transactional leadership: a meta-analysis. Journal of applied psychology, 89(5), 901.

Braveman, P. (2006). Health disparities and health equity: concepts and measurement. Annu. Rev. Public Health, 27, 167-194.

Brown, T., Williams, B., \& Jolliffe, L. (2014). Leadership style preference of undergraduate occupational therapy students in Australia. Hong Kong Journal of Occupational Therapy, 24(1), 35-42.

Cardinal, L. B., Kreutzer, M., \& Miller, C. C. (2017). An aspirational view of organizational control research: Re-invigorating empirical work to better meet the challenges of 21st century organizations. Academy of Management Annals, 11(2), 559-592.

Chen, S. Y., Wu, W. C., Chang, C. S., Lin, C. T., Kung, J. Y., Weng, H. C., ... \& Lee, S. I. (2015). Organizational justice, trust, and identification and their effects on organizational commitment in hospital nursing staff. BMC health services research, 15(1), 363.

Cohen, L., Manion, L., \& Morrison, K. (2000). Research methods in education [5 ${ }^{\text {th }}$ ed.] London: Routledge Falmer. Teaching in Higher Education, 41, 21.

Cooper, D. R., \& Schindler, P. S. (2014). Business Research Methods. The McGraw- Hill Companies.

Creswell, J. W., \& Clark, V. L. P. (2017). Designing and conducting mixed methods research. Sage publications.

Dudek-Shriber, L. (1997). Leadership qualities of occupational therapy department program directors and the organizational health of their departments. American Journal of Occupational Therapy, 51(5), 369-377.

Eisenhardt, K. M. (1989). Building theories from case study research. Academy of management review, 14(4), 532-550.

Elrehail, H., Emeagwali, O. L., Alsaad, A., \& Alzghoul, A. (2018). The impact of transformational and authentic leadership on innovation in higher education: the contingent role of knowledge sharing. Telematics and Informatics, 35(1), 55-67.

Emery, C. R., \& Barker, K. J. (2007). The effect of transactional and transformational leadership styles on the organizational commitment and job satisfaction of customer contact personnel. Journal of Organizational Culture, Communication and Conflict, 11(1), 77-90. 
Fang, C. H., Chang, S. T., \& Chen, G. L. (2009). Applying Structural Equation Model to Study of the Relationship Model among leadership style, satisfaction, Organization commitment and Performance in hospital industry. In 2009 International Conference on E-Business and Information System Security.

Fink, A. S. (2000). The role of the researcher in the qualitative research process. A potential barrier to archiving qualitative data. Forum: Qualitative Social Research, 1(3), Art. 4.

Gottfredson, R. K., \& Aguinis, H. (2017). Leadership behaviors and follower performance: Deductive and inductive examination of theoretical rationales and underlying mechanisms. Journal of Organizational Behavior, 38(4), 558-591.

Goh, Y. V., \& Soutar, G. (2005). The role of ethical behaviours in the relations between leadership styles and job performance. In The Role of Ethical Behaviours in the Relations between Leadership Styles and Job Performance (pp. CR-24). Promaco Conventions Pty. Ltd.

Guba, E. G., \& Lincoln, Y. S. (1994). Competing paradigms in qualitative research. Handbook of qualitative research, 2(163-194), 105.

Kelly, S., \& MacDonald, P. (2019). A look at leadership styles and workplace solidarity communication. International Journal of Business Communication, 56(3), 432-448.

Kvale, S., \& Brinkmann, S. (2009). Interviews: Learning the craft of qualitative research. California, US: SAGE, 230-243.

Lepak, D. P., Liao, H., Chung, Y., \& Harden, E. E. (2006). A conceptual review of human resource management systems in strategic human resource management research. Research in Personnel and Human Resources Management, 25(1), 217-271.

Lincoln, A., \& Keller, H. (2018). Building Teams, Adaptive and Situational Leadership, and Leadership Power. Boston Academic Publishing.

Linehan, P. M. (2017). The Culture of Leadership in Contemporary China: Conflict, Values, and Perspectives for a New Generation. Lexington Books.

Lo, M. C., Ramayah, T., Min, H. W., \& Songan, P. (2010). The relationship between leadership styles and organizational commitment in Malaysia: Role of leader-member exchange. Asia Pacific business review, 16(1-2), 79-103.

Morrow, S. L. (2005). Quality and trustworthiness in qualitative research in counseling psychology. Journal of Counseling Psychology, 52(2), 250.

Morrow, S. L., \& Smith, M. L. (2000). Qualitative research for counseling psychology. Handbook of counseling psychology, 3, 199-230.

Nasurdin, A. M., Ahmad, H. N., \& Razalli, A. (2014). Politics, Justice, Stress, And Deviant Behaviour in Organizations: An Empirical Analysis. International Journal of Business \& Society, 15(2).

Nugus, P., Ranmuthugala, G., Lamothe, J., Greenfield, D., Travaglia, J., Kolne, K., ... \& Braithwaite, J. (2018). New ways to get policy into practice. Journal of health organization and management, 32(6), 809-824.

Othman, J., Mohammed, K. A., \& D'Silva, J. L. (2013). Does a transformational and transactional leadership style predict organizational commitment among public university lecturers in Nigeria?. Asian Social Science, 9(1), 165.

Patton, M. Q. (2014). Qualitative research \& evaluation methods: Integrating theory and practice. Sage publications.

Peachey, G. A. (2002). The effect of leader empowering behaviours on staff nurses workplace empowerment, psychological empowerment, organizational commitment, and absenteeism (Doctoral dissertation). 
Podsakoff, P. M., MacKenzie, S. B., Moorman, R. H., \& Fetter, R. (1990). Transformational leader behaviors and their effects on followers' trust in leader, satisfaction, and organizational citizenship behaviors. The Leadership Quarterly, 1(2), 107-142.

Rad, A. M. M., \& Yarmohammadian, M. H. (2006). A study of relationship between managers' leadership style and employees' job satisfaction. Leadership in Health Services.

Rehman, S., Shareef, A., Mahmood, A., \& Ishaque, A. (2012). Perceived leadership styles and organizational commitment. Interdisciplinary Journal of Contemporary Research in Business, 4(1), 616-626.

Reiter-Palmon, R., \& Illies, J. J. (2004). Leadership and creativity: Understanding leadership from a creative problem-solving perspective. The Leadership Quarterly, 15(1), 55-77.

Sekaran, U., \& Bougie, R. (2016). Research methods for business: A skill building approach. John Wiley \& Sons.

Snodgrass, J., Douthitt, S., Ellis, R., Wade, S., \& Plemons, J. (2008). Occupational therapy practitioners' perceptions of rehabilitation managers' leadership styles and the outcomes of leadership. Journal of Allied Health, 37(1), 38-44.

Silverman, D. (2013). Doing qualitative research: A practical handbook. SAGE publications limited.

Stockdale, J., \& LeMay, S. G. (2001). U.S. Patent No. 6,251,014. Washington, DC: U.S. Patent and Trademark Office.

Voon, M. L., Lo, M. C., Ngui, K. S., \& Ayob, N. B. (2011). The influence of leadership styles on employees' job satisfaction in public sector organizations in Malaysia. International Journal of Business, Management and Social Sciences, 2(1), 24-32.

Walliman, N., \& Walliman, N. (2010). Research Methods: The Basics. Taylor and Francis.

Yiing, L. H., \& Ahmad, K. Z. B. (2009). The moderating effects of organizational culture on the relationships between leadership behaviour and organizational commitment and between organizational commitment and job satisfaction and performance. Leadership \& Organization Development Journal, 30(1), 53-86.

Yin, R. K. (2017). Case study research and applications: Design and methods. Sage publications.

Yukl, G. (2012). Effective leadership behavior: What we know and what questions need more attention. Acad Manage Perspect, 26, 66-85. 